\title{
VICISSITUDES DE UM INSPETOR DE DISTRITO EM SOROCABA, EM MEADOS DO SÉCULO XIX
}

\section{Wilson Sandano \\ UNISO}

Em nossa pesquisa sobre a formação da educação escolar em Sorocaba, consultamos documentação constituída por ofícios, cartas e memorandos de professores, inspetores de distrito e Inspetor Geral da Instrução Pública, na segunda metade do século XIX. Esta documentação foi obtida, pela Universidade de Sorocaba junto ao Arquivo Histórico do Estado de São Paulo e se constitui em xerocópia dos originais.

Os documentos que apresentamos são transcrições de duas cartas do Inspetor de Distrito de Sorocaba, Joaquim José Loureiro d'Almeida, ao Inspetor Geral da Instrução Pública, datadas de 3 de fevereiro de 1885, em que pede demissão de seu cargo de Inspetor de Distrito, e a resposta do Inspetor Geral da Instrução Pública, datada de 17 de fevereiro de 1855 .

Queremos registrar que o Sr. Joaquim José Loureiro d'Almeida exerceu as funções de Inspetor de Distrito entre agosto de 1853 e dezembro de 1855. Em 7 dezembro os ofícios da Inspetoria de Distrito já são firmados por Américo Brasiliense de Almeida Mello.

Para finalizar, queremos relembrar, quanto à inspeção escolar, a manifestação do Dr. José Thomaz Nabuco D’Araujo, Presidente da Província de São Paulo, em seu relatório à Assembléia Legislativa Provincial:

Ainda não eram passados dous mezes depois que tomei conta da administração, e já eu reconhecia a sabedoria e providencia que dictarão a lei Provincial n. 24 de 2 de junho de 150 art. $4 .^{\circ}$, que autorisa ao governo a dar regulamentos ao ensino primario e secundario da Provincia, podendo alterar a legislação em vigor somente na parte relativa á inspeção do mesmo ensino. Assim um dos primeiros actos de minha administração foi a confecção do Regulamento de 8 de novembro de 1851, o qual submetto á vossa consideração.

A inspecção do ensino primario e secundario competia pela legislação, que então vigorava, ás comissões inspectoras e camaras muncipaes: a experiencia faz sentir que as pessoas moraes não são as mais proprias para administrar, falta-lhes a unidade de pensamento na deliberação, a actividade, e prontidão na acção: sobre-leva que a organisação dessas commissões inspectoras era essencialmente vicioza, por que o Governo não podia inspirar-lhes o seu pensamento, visto como só um dos seus membros era da nomeação delle: de origem diversa, independentes, erão as mais das vezes riváes: dahi a hostilidade, ou inercia que embargavão a fiscalisação: não era possivel que continuassem essas commisões, que, pela maior parte, não se reunião, e nada fazião. Parece-me que traduzi com a fidelidade possivel o espirito da lei, encarregando a inspecção do ensino primario e secundario a pessoas fisicas, da confiança do Governo, susceptiveis do mesmo pensamento administrativo, e capazes d'executalo: fôra contra senso suppôr o Governo suspeito á instrucção publica, fôra 
absurdo tornal-o estranho á essa uma das primeiras necessidades moraes do paiz.

Quanto á fiscalisação as ideias do Regulamento, para cujo desenvolvimento fora de mister um grosso volume, tem por si a autoridade da legislação dos paizes mais cultos da Europa, o exemplo de outras provincias importantes, e são conformes e consentaneas ao espirito da novisima lei geral n. 630 de 17 de setembro de 1851 (SÃO PAULO [PROVINCIA] 1852, p. 10-11). ${ }^{1}$

${ }^{1}$ GONZÁLEZ, Jorge Luís Cammarano; SANDANO, Wilson. A formação da educação escolar pública em Sorocaba - 1850-1880. Revista HISTEDBR On-Line, Campinas, n. 16, p. 36-360, dez. 2004. 


\section{OFÍCIO ENCAMINHADO AO INSPETOR GERAL DA INSTRUÇÃO PÚBLICA, POR JOAQUIM JOSÉ LOUREIRO D'ALMEIDA, INSPETOR DE DISTRITO, EM 3 DE FEVEREIRO DE 1855.}

$\mathrm{III}^{\mathrm{mo}}$. $\mathrm{S}^{\mathrm{r}}$. $\mathrm{D}^{\text {or }}$. Diogo de Mendonça Pinto

Sora. 3 de Fevo. de 1855

Estimarei que $V \mathrm{~S}$ a. com percurso (?) do anno novo continue a prosperar como opreterito. Incluso remetto a $\vee$ Sa. o offo. que junto achará pạ. me fazer ofavor de implorar ao Ex ${ }^{m o}$. Governo mª. demissão do Emprego de Inspector de Distro. visto que me axo cansado de trabalhar no mundo politico onde debalde tenho prodigalizado meos cuidados: $\mathrm{Sr}$ (?) porem hoje cançado, ja velho só me restão os incomodos. $\mathrm{P}^{\text {or }}$ tanto este pequeno espaço detempo que me resta da vida desejo dedicar aos encantos dehu'a vida privada ecuidar de ajuntar pão $p$ a. minha numerosa fama.., que mefoi confiada pela Providencia. Aproveito esta $\mathrm{m}^{\text {ma }}$. Occazião deagradecer a V $\mathrm{s}$ a. adelicadeza comque sempre tratoume pela sua nimia bondade e igualm ${ }^{e}$. offerecerlhe omeo limitado prestimo nesta $\mathrm{Cid}^{\mathrm{e}}$.; nacerteza deque posso ser

$\mathrm{Am} \times$

Joaquim Joze Louro. $d^{\prime} A l m^{\text {da }}$. 


\section{OFÍCIO ENCAMINHADO AO PRESIDENTE DA PROVÍNCIA, POR JOAQUIM JOSÉ LOUREIRO D'ALMEIDA, INSPETOR DE DISTRITO, EM 3 DE FEVEREIRO DE 1855.}

III ${ }^{\text {mo }}$. e Ex ${ }^{\text {mo }} \cdot \mathrm{Snr}^{\prime}$

Achandome resedindo em meo Engenho distante desta Cidade quatro legoas esempre em continuo soffrimento demolestias, que acompanhão ao homem quinquagenario, forçoso me he reccorrerme a $\mathrm{V} \mathrm{Ex}$. . pedindo dispensa de mais poder continuar no exercicio de Inspector de Districto, que adois annos tenho exercido e espero merecer de $\mathrm{V} \mathrm{Ex}^{\text {ca }}$. esta graça; visto a impossibilidade enqo meacho pelos motivos Supra mencionados.

Deos $G^{e}$ a V Ex ${ }^{\text {ca }}$ como he mister.

Sorạ. 3 de Fevo. de 1855

III ${ }^{\mathrm{mo}}$. e Ex ${ }^{\mathrm{mo}}$. Snr'. Prez ${ }^{\mathrm{e}}$. desta Prova .

Joaquim Joze Loureiro d'Almeida

Inspector de Distro. 


\section{OFÍCIO ENCAMINHADO AO INSPETOR DE DISTRITO PELO INSPETOR GERAL DA INSTRUÇÃO PÚBLICA, EM 17 DE FEVEREIRO DE 1855.}

$I I I^{m o} . S^{r}$. Joaq ${ }^{m}$. (?) Lour ${ }^{\circ}$. d'Almd $d^{a}$. (?)

Tendo a honra de ser nomeado $p^{\text {a }}$. assumir interinament. (?) o lugar de Insp ${ }^{\text {or }}$. Geral da Instr ${ }^{\text {cão }}$. (?) Publica, achei hua Carta de V. S. ao $S^{r}$. $D^{\text {or }}$. Diogo em que pede instantement. a Demissão do Emprego de Insp ${ }^{\text {or }}$. desse Distr ${ }^{\circ}$. As razoens q. V. S. allega são $\mathrm{m}^{\text {to }}$. attendiveis, mas o serv ${ }^{\circ}$. publico merece tambem $\mathrm{m}^{\text {ta }}$. fe na atividade e bond. (??); e se p. ventura (?) tenho alguém (???) per. (?) V. S. empenho-o (??) toda (?) p. q. V. S. continue no $\mathrm{m}^{\text {mo }}$. Emprego, e serão sempre considerados por mim como relevantes os serviços q. V. S. continua a prestar.

Este Emprego de Insp ${ }^{\text {or }}$. não he possivel q. se entregue a homem sem prestigio, e q. não se interessa $\mathrm{p}^{\mathrm{la}}$. Instr ${ }^{\mathrm{am}}$. da mocidade. (???) q. tanto concorrem (?) na pessoa de V. S. Por outro lado o Emprego não he tão pezado q. prive ao Cidadão q. o ocupa de outros affazeres. Por isso servindo ao Publico, tem o devido tempo $p^{a}$. o descanso de seus annos.

Espero merecer de V. S. este obsequio, e todo me offereço $p^{a}$. o seu serv ${ }^{\circ}$., na certeza de que sou com toda a consideração.

S. $P^{\text {lo }} .17$ de Fevr ${ }^{\circ}$. de 55

De V.S.

$A m^{\circ}$. (?) e $\mathrm{m}^{\text {to }} \cdot \mathrm{obr}^{\circ}$. (???)

H. H. Ferraz (?) 